\title{
A MIGRAÇÃO, SOB O ENFOQUE DA GLOBALIZAÇÃO: ANÁLISE DO FLUXO MIGRATÓRIO EM MATO GROSSO DO SUL 2011 - 2016
}

\author{
Daniela Estolano Francelino ${ }^{1}$ \\ Luciani Coimbra de Carvalho ${ }^{2}$
}

\begin{abstract}
RESUMO: Muitos estrangeiros acabam por buscar o Estado Brasileiro como recanto para a preservação dos direito sociais. Este trabalho tem como objetivo essencial analisar a migração, sob a perspectiva da globalização. Detêm, outrossim, objetivos específicos de: identificar o fenômeno da migração frente à globalização; demonstrar os principais direitos sociais resguardados aos migrantes; e analisar o Fluxo Migratório de Mato Grosso do Sul, na perspectiva dos direitos sociais. O presente estudo fora conduzido mediante uma pesquisa exploratória, descritiva e bibliográfica, sendo adotado o método dedutivo. O intuito é tornar perceptíveis as ferramentas positivadas que levam a preservação dos direitos fundamentais.
\end{abstract}

Palavras-chave: Globalização; Migração; Direitos Sociais; Mato Grosso do Sul; Direitos Humanos.

\section{THE MIGRATION, UNDER THE GLOBALIZATION APPROACH: ANALYSIS OF MIGRATORY FLOW IN MATO GROSSO DO SUL 2011 - 2016}

\begin{abstract}
Many foreigners eventually seek the Brazilian State as a place for the preservation of social rights. This paper aims to analyze migration from the perspective of globalization. The specifiv objectives: identify the phenomenon of migration in the face of globalization; demonstrate the main social rights protected to the migrants; and to analyze the Migratory Flow of Mato Grosso do Sul, in the perspective of social rights. The study was carried out through an exploratory and bibliographic. The intention is to make perceptible the positive tools that lead to the preservation of fundamental rights.
\end{abstract}

Keywords: Globalization; Migration; Social Rights; Mato Grosso do Sul; Human Rigths.

\footnotetext{
${ }^{1}$ Graduada em Direito pela Universidade Federal de Mato Grosso do Sul. Mestranda, bolsista CAPES, no Programa de Pós-Graduação Strictu Sensu em Direito, Universidade Federal de Mato Grosso do Sul. Integrante do Grupo de Pesquisa: Análise do Tráfico de Pessoas e Migração na Fronteira de Mato Grosso do Sul - Dinâmicas e Modalidades (2012/2016). E-mail: dani.estolano@ @otmail.com. Telefone: (66) 9-9629-0305.

${ }^{2}$ Graduada em Direito pela Universidade Católica Dom Bosco. Mestrado e Doutorado em Direito pela PUC/SP. Professora do Mestrado PROFIAP e do Mestrado em Direito da UFMS. Docente do DINTER USP/UFMS. Coordenadora do Grupo de Pesquisa: Análise do Tráfico de Pessoas e Migração na Fronteira de Mato Grosso do Sul - Dinâmicas e Modalidades (2012/2016). E-mail: lucianicoimbra@ hotmail.com. Telefone: (67) 9-8178-6006.
} 


\section{INTRODUÇÃO}

Os aspectos dos fluxos migratórios estão comumente interligados às influências da globalização que motivam os estrangeiros a buscarem outros estados como recantos para a preservação de garantias e direitos, todavia, os migrantes ao adentrarem as fronteiras do Estado brasileiro se deparam com a escassez de informações legislativa acerca dos direitos que lhe são conferidos, e na maioria dos casos, pela condição socioeconômica que se encontram, rendemse às diversas modalidades de exploração; eis que apenas, deste modo, conseguem subsídios básicos para proverem a subsistência.

A presente pesquisa se justifica em virtude da quantidade de migrantes que o Brasil tem recebido e a recente publicação de Lei de Migração e tem como objetivo essencial analisar a migração, sob a perspectiva da globalização com objetivos específicos de: a) identificar o fenômeno da migração frente à globalização; b) demonstrar os principais direitos sociais dos migrantes; e c) analisar o Fluxo Migratório de Mato Grosso do Sul na perspectiva dos direitos sociais.

A metodologia de pesquisa quanto aos fins, é descritiva, explicativa e exploratória, cujo principal intuito é identificar os mecanismos empenhados pelo Estado brasileiro na busca da proteção dos direitos aos migrantes; sendo adotado o método dedutivo, com a descrição, compreensão, explicação e definição de conceitos, com premissas e conclusões inerentes às políticas frente aos migrantes.

E, ainda, quanto aos meios, na esfera bibliográfica e documental, com análise de artigos e revistas científicas, destacando-se a utilização de materiais relativos aos Direitos Humanos, à Política Migratória, ao Direito Constitucional, aos Direitos Humanos Fundamentais, na busca da resolução do objetivo geral e objetivos específicos delimitados.

\section{INFLUÊNCIA DA GLOBALIZAÇÃO À MIGRAÇÃO}

A globalização é um dos processos de aprofundamento internacional da integração econômica, social, cultural e política, suas características refletem, diretamente, na ordem mundial, nas relações dos países e na dinâmica de toda a sociedade global, por ocorrer uma grande troca entre os países, por isso estes acabam por ser conectar por natureza bem peculiar, repercutindo em todas as ações (TORRADO, 2016, p. 47).

Para muitos doutrinadores, a globalização é um dos principais fatores que influenciam a migração, principalmente, quando se refere a questão de ordem econômica, facilitando, 
destarte, interferência na dinâmica da movimentação dos indivíduos pelo continente. Para Boaventura de Souza Santos (1997, p. 7) "a globalização implica na modificação da compreensão do espaço-tempo, abalando os processos de transformação social pelo Mundo", desta forma, o instituto da migração é oriundo das transformações geradas pelo desenvolvimento histórico.

Em consequência do fenômeno da globalização econômica, o fluxo migratório intensificou-se, além disso, acordos econômicos celebrados entre alguns países causaram a ruptura da barreira geográfica, ocasionando, desta feita, maior transação dos cidadãos entre os Estados (OLIVEIRA; GOMES; GONÇALVES, 2017, p. 363 e p. 365). Deve-se ressaltar que, desde o Tratado de Lisboa, firmado em 2007, por diversos países, cujo principal alvo fora a cooperação entre os signatários, fora oportunizada a ruptura da fiscalização fronteiriça aumentando o fluxo de indivíduos pelo globo (FERNANDES; SILVEIRA, 2017, p. 211-212).

É notável pelos quadros estatísticos da ACNUR, ONU e OIM o aumento exponencial do índice de migração, sendo este provocado por diversas razões econômica, social, ambiental, política, entre outras, bem como a identificação de que a os fenômenos migratórios ocorrem em conformidade com o contexto histórico, situações e os acontecimentos de cada geração, sejam por questões sociais, por fatores econômicos - um dos maiores atrativos das metrópoles -, pelo fator político, quando houver influência de feitos governamentais, fornecendo maior atrativo referente à amplitude de direitos sociais (BAENINGER, 1998, p. 73).

Nesse contexto, os países aonde existem desigualdades entre os cidadãos, disputas políticas, falta de direitos, apresentam-se como os principais impulsionadores do movimento populacional entre os Estados (GOIS, 2018, p. 48), que fazem com que, os migrantes saiam de seus lares em busca de oportunidades e facilidades para o desenvolvimento físico, mental, moral, espiritual e social.

Por outro lado, os países que recebem migrantes, dependem da eficácia de fomentos governamentais para que os principais direitos sejam protegidos independentemente da nacionalidade, estando no rol de direito, os direitos sociais.

A presente pesquisa tem por objeto delimitado a entrada de migrantes pelo Estado do Mato Grosso do Sul que faz fronteira com dois países, Paraguai e Bolívia, possuindo várias cidades gêmeas e uma longa faixa de fronteira seca. 
3 ANÁLISE DO FLUXO MIGRATÓRIO DO ESTADO DE MATO GROSSO DO SUL NO PERÍODO COMPREENDIDO ENTRE 2011 A 2016 - NA PERPECTIVAS DOS DIREITOS SOCIAIS

Será abordada investigação do número de migrantes que adentraram a fronteira do Estado de Mato Grosso do Sul, cuja extensão está compreendida pelas cidades de Corumbá, Ponta-Porã e Novo Mundo. Referidos dados foram fornecidos pelo representante competente da DPF/CRA/MS - Delegacia da Polícia Federal. Há, ainda, averiguação das informações obtidas no Instituto Brasileiro de Geografia e Estatística.

O Estado de Mato Grosso do Sul está localizado na região Centro-Oeste, esta composta, ainda, pelo Distrito Federal e os estados de Goiás e Mato Grosso. A sua extensão territorial na porção lateral esquerda é traço fronteiriço com os países vizinhos - Bolívia e Paraguai. Insta acentuar que, a região de divisa com os países adjacentes é monitorada pela Polícia Federal, donde se têm postos aduaneiros, cuja funções são a realização do controle da importação e exportação de produtos, basta mirar por se tratar de região de fronteiriça.

Tal qual preceitua o art. $20^{3}, \S 2^{\circ}$, da $\mathrm{CF}$, a região com distância de até $150 \mathrm{~km}$ (cento e cinquenta quilômetros) das faixas fronteiriças são consideradas fundamentais para a defesa do território nacional, desta feita, para utilizá-las, ser proprietário, é essencial conter a observância de diversas leis especiais que irão dispor regras com o intento de proteger a ordem da nação (BRASIL, 1988).

\subsection{Ponto de Migração Terrestre em Corumbá - Mato Grosso do Sul}

Corumbá está situado na porção do pantanal Sul-Mato-Grossense, os países abarcadores de seus limites fronteiriços - Paraguai e Bolívia. Alcança, hodiernamente, 109.294 mil habitantes. Alguns países da América do Sul estão passando por grande crise política, sendo um dos principais fatores geradores do grande fluxo migratório.

Em balanço às fontes obtidas, cerca de 209.887 bolivianos - adentraram o Estado de

\footnotetext{
${ }^{3}$ Art. 20. São bens da União:

$[\ldots]$

$\S 1^{\circ}$ É assegurada, nos termos da lei, aos Estados, ao Distrito Federal e aos Municípios, bem como a órgãos da administração direta da União, participação no resultado da exploração de petróleo ou gás natural, de recursos hídricos para fins de geração de energia elétrica e de outros recursos minerais no respectivo território, plataforma continental, mar territorial ou zona econômica exclusiva, ou compensação financeira por essa exploração.

$\S 2^{\circ}$ A faixa de até cento e cinquenta quilômetros de largura, ao longo das fronteiras terrestres, designada como faixa de fronteira, é considerada fundamental para defesa do território nacional, e sua ocupação e utilização serão reguladas em lei.
} 
MS - pela fronteira Corumbaense, no período de 2011 a 2016; as principais razões para este elevado número de migrantes estão caracterizadas pela proximidade da faixa terrestre, e, ainda, pela incessante busca por melhores condições de vida; é essa procura está, sempre, interligada aos direitos sociais.

Abaixo segue gráfico que demonstra o número de migrantes, no período de 05 anos, em harmonia alhures mencionado, perfazendo um total de 325.032 pessoas.

Ponto de Migração Terrestre em Corumbá - Mato Grosso do Sul, Brasil, 2011 a 2016

\begin{tabular}{lll}
\hline País de Nacionalidade & Números de Migrantes & Porcentagem (\%) \\
\hline Bolívia & 209887 & 64,57 \\
\hline Brasil & 66448 & 20,46 \\
\hline Peru & 12997 & 4,00 \\
\hline Paraguai & 9257 & 2,85 \\
\hline Chile & 2791 & 0,86 \\
\hline Argentina & 2551 & 0,78 \\
\hline Reino Unido & 2244 & 0,69 \\
\hline Colômbia & 2163 & 0,67 \\
\hline França & 1864 & 0,57 \\
\hline Alemanha & 1832 & 0,56 \\
\hline Outros & 12958 & 3,99 \\
\hline Total & $\mathbf{3 2 5 0 3 2}$ & $\mathbf{1 0 0 , 0 0}$ \\
\hline
\end{tabular}

Fonte: Elaboração própria, com base nos dados da Delegacia da Polícia Federal de Corumbá, DPF/CRA/MS.

A saúde é um dos principais elementos buscados pelos migrantes, sendo considerado um direito fundamental ao ser humano. Na supradita lei, não persevera distinção concernente aos cidadãos, sejam estes brasileiros - natos ou naturalizados -, ou migrantes (BRASIL, 1990).

Nas regiões de fronteiras a incidência para tratamento médico é elevada, justamente, pelo fato de sobrevir grande fluxo migratório, com contínua ida e vinda, seja por razões familiares, trabalho, escola, entre outras. Para que detenha a prestabilidade de saúde é fundamental, na maioria dos centros médicos, a apresentação do comprovante de residência a grande dificuldade faz-se pela transitoriedade de alguns indivíduos e a falta de regularização documental - motivando, assim, o não acesso. (GIOVANELLA, 2007, p. 256). 
O último censo realizado pelo Instituto Brasileiro de Geografia e Estatística, indica, a amostra de residentes na cidade de Corumbá/MS, no importe de 102.421 brasileiros natos, 546 naturalizados e 736 habitantes de nacionalidade estrangeira, ocasionando um total de 103.703 habitantes (IBGE, 2010). É evidente controvérsia sobre o do fornecimento dos direitos sociais aos migrantes, mas não se pode olvidar, em exploração as legislações específicas, em seus arranjos, não prospera diferenças entre os indivíduos.

\subsection{Ponto de Migração Terrestre em Ponta Porã - Mato Grosso Do Sul}

Ponta Porã é um munícipio que reúne o número de habitantes na compreensão de 88.164 pessoas, Paraguai lhe faz limite territorial. Uma das principais fontes de renda do referido município é o comércio (IBGE, 2010). Recorrente é a prática de utilização de labor estrangeiro, em muitas situações ocorre a exploração da referida mão de obra, em razão da falta de discernimento do manto legislativo doméstico, muitas vezes são obrigados e submetidos a trabalhos desumanos.

Pedro Juan Caballero, cidade situada no Paraguai, constitui malha urbana com PontaPorã - MS, em consequência da quase união das cidades na faixa de fronteira é comum a entrada e saída de trabalhadores - em ambas as cidades. Os materiais do IBGE (2010), demonstram que, cerca de 1.771 pessoas nutrem local de trabalho em país estrangeiro. Suplica salientar, a principal causa é em decorrência da viabilidade de oferta de trabalho encontrada nas proximidades.

O número de migrantes que trespassaram a fronteira de Ponta-Porã no período de 2011 a 2016, chega a 88.697 pessoas, contemple quadro a seguir:

Ponto de Migração Terrestre em Ponta Porã - Mato Grosso do Sul, Brasil, 2011 a 2016

\begin{tabular}{lll}
\hline País de Nacionalidade & Números de Migrantes & Porcentagem $(\%)$ \\
\hline Paraguai & 72843 & 82,13 \\
\hline Brasil & 8826 & 9,95 \\
\hline Argentina & 2535 & 2,86 \\
\hline Bolívia & 618 & 0,70 \\
\hline Chile & 588 & 0,66 \\
\hline México & 506 & 0,57 \\
\hline Alemanha & 351 & 0,40 \\
\hline
\end{tabular}




\begin{tabular}{lll}
\hline Japão & 203 & 0,23 \\
\hline Espanha & 199 & 0,22 \\
\hline Colômbia & 193 & 0,22 \\
\hline Outros & 1835 & 2,07 \\
\hline Total & $\mathbf{8 8 6 9 7}$ & $\mathbf{1 0 0 , 0 0}$
\end{tabular}

Fonte: Elaboração própria, com base nos dados da Delegacia da Policia Federal de Corumbá, DPF/CRA/MS.

A maior incidência de migrantes são paraguaios, no período quinquenal pesquisado, o número chega a 72.843 indivíduos. A fronteira com o Paraguai é muito utilizada não só por cidadãos oriundos dos países da América do Sul, mas, também, por norte-americanos, da mesma maneira tabela supradita, indica cerca de 506 mexicanos ingressantes.

Divergência pertinente à migração refere-se à discriminação, exploração e xenofobia sofrida pelos migrantes, pincipalmente, a mão-de-obra migrante utilizada, em algumas situações, sem observância às regras previstas pela Consolidação das Leis do Trabalho.

Submetidos ao trabalho análogo ao escravo, com jornadas superiores a 12 horas diárias, residindo em locais insalubres, com alimentação de baixo nível. O Ministério Público do Trabalho, juntamente, com o Ministério do Trabalho e Emprego, a Polícia Federal e o Ministério Público Federal, estão atuando de forma preventiva, realizando fiscalizações em ambientes de trabalhos, seja de maneira ordinatória ou em face de denúncias. (BRASIL, 2013, p. 19)

Quando verificado que realmente subsiste emprego degradante, os representantes do Ministério Público do Trabalho, em conjunto com a Polícia Federal, atuarão de forma repressiva, na maioria das ocorrências o estabelecimento é ocluso, o migrante é submetido à entrevista para verificação da sua situação jurídica, em alguns casos procederá, quando viável, a regularização do migrador, ou ocorrerá a volta deste para casa (BRASIL, 2013, p. 19 e p. 2223).

Ao responsável pelo empreendimento - o empregador - será aplicada multa a partir da ocorrência do fato denunciado. A competência para tramitação das ações penais demandadas é a Justiça Federal, os principais tipos penais assentados no Código Penal Brasileiro, estão no art. 149, vejamos a disciplina:

Reduzir alguém a condição análoga à de escravo, quer submetendo-o a trabalhos forçados ou a jornada exaustiva, quer sujeitando-o a condições 
degradantes de trabalho, quer restringindo, por qualquer meio, sua locomoção em razão de dívida contraída com o empregador ou preposto [...]. (BRASIL, 1940).

Se o referido crime for cometido pelo propósito de preconceito à raça, cor, religião, etnia ou origem, a pena será aumentada pela metade, a pena máxima é de 08 anos - serão acrescidos mais 04 anos. Assim, é visto que, é evidenciado com atenção esta situação ocorrida (BRASIL, 1940).

Ponta-Porã, em conformidade com os números do IBGE (2010), apresenta a população de 77.872, abrangendo os seguintes números pertencentes à nacionalidade dos indivíduos, 75.114 brasileiros-natos, 619 brasileiros-naturalizados e 2.139 estrangeiros. É possível auferir que, aproximadamente, $3 \%$ dos cidadãos são estrangeiros, ocasionando contribuição e impacto na economia, renda per capita, saúde, densidade demográfica, produto interno bruto, índice de desenvolvimento humano do referido município.

\subsection{Ponto de Migração Terrestre em Mundo Novo - Mato Grosso do Sul}

O município de Mundo Novo, localizado, na porção sudoeste, do Estado de Mato Grosso do Sul, contém confrontação territorial com o estado do Paraná, na região sul, e com o Paraguai, na região oeste. Muito embora, no período de 05 anos, configure o registro de apenas dois migrantes - modo a tabela a seguir - divergem com os elementos do Instituto Brasileiro de Geografia e Estatística, demonstrando que, apenas, os sujeitos naturalizados, alcançam o importe de 157 pessoas (IBGE, 2010).

Ponto de Migração Terrestre em Mundo Novo - Mato Grosso do Sul, Brasil, 2011 a 2016

\begin{tabular}{lll}
\hline País de Nacionalidade & Números de Migrantes & Porcentagem (\%) \\
\hline Paraguai & 2 & 100,00 \\
\hline Total & $\mathbf{2}$ & $\mathbf{1 0 0 , 0 0}$
\end{tabular}

Fonte: Elaboração própria, com base nos dados da Delegacia da Policia Federal de Corumbá, DPF/CRA/MS.

Para advir a naturalização é indispensável o início do procedimento jurídico e o preenchimento de alguns requisitos. A naturalização pode ser ordinária, da qual será concedida ao migrante, desde que preencha os seguintes requisitos: a) ter capacidade civil segundo a legislação brasileira; b) ter residência contínua no Brasil por no mínimo 04 anos; c) realizar a 
comunicação por Língua Portuguesa será observada a condição do naturalizado; e d) não podendo atestar condenação na esfera penal (BRASIL, 2017).

Referido prazo de 04 anos de domicílio poderá ser reduzido para, no mínimo, 01 ano, desde que preencha as condições de: a) tiver descendente brasileiro; b) houver ou puder prestar atividade relevante ao Brasil; c) caso o indivíduo leve capacidade técnica, científica; ou d) no momento da naturalização ser cônjuge ou companheiro de brasileiro (BRASIL, 2017).

Assevera, também, a Constituição Federal, a naturalização extraordinária ou simplificada, em inteligência do art. 12, inc. II, alínea b, da Magna Carta, é basilar que o indivíduo, seja qual for a nacionalidade, 15 anos de residência, de modo ininterrupto, sem nenhuma forma de condenação penal. O procedimento será iniciado, apenas, quando houver provocação (BRASIL, 1988).

Importa-se outras duas formas de naturalização, quais sejam, a naturalização especial e a provisória; explique-se, aquela ocorre quando houver o preenchimento das seguintes hipóteses: se o indivíduo for cônjuge - pelo período de 05 anos - de diplomata, funcionário da embaixada ou consulado brasileiro; ou houver sido empregado em representação diplomática ou em ambiente consular no Brasil. A provisória, ordenada no art. 116, da Nova Lei de Migração, ensina, aos migrantes com 10 anos de idade incompletos, e que figurem residência fixa no Brasil, poderão requerer a naturalização pela via de um representante legal (BRASIL, 2017).

\section{DIREITOS SOCIAIS PREVISTOS NA LEGISLAÇÃO BRASILEIRA QUE RESGUARDAM A PROTEÇÃO DO MIGRANTE}

O levantamento apresentado sobre o fluxo migratório no Estado do Mato Grosso do Sul é anterior a Lei de Migração (Lei n. 13455/2017), que substituiu o Estatuto do Estrangeiro (Lei n. 6.815/1980), do qual não exibia os direitos sociais redigidos de forma expressa, apenas algumas menções implícitas; e, na maioria dos casos, por ter cunho de segurança nacional detinha diversos requisitos burocráticos para a concessão dos principais direitos sociais.

Todavia, o perfil do migrante que cruza a fronteira de Mato Grosso do Sul, é justamente de indivíduo que depende da eficácia de direitos sociais previstos no ordenamento jurídico brasileiro, em virtude da vulnerabilidade social em que se encontram.

A Lei de migração brasileira é composta por 125 artigos, dos quais, 12 destes ostentam de feitio explícito ordenações atinentes aos Direitos Sociais previstos no art. $6^{\circ}$, da Magna 
Carta. Sendo composta da seguinte estrutura: 10 Capítulos, com as seguintes nomenclaturas I. Disposições Preliminares; II. Da Situação Documental do Migrante e do Visitante; III. Da Condição Jurídica do Migrante e do Visitante; IV. Da Entrada e Saída do Território Nacional; V. Das Medidas de Retirada Compulsória; VI. Da Opção de Nacionalidade e Naturalização; VII. Do Migrante; VIII. Das Medidas de Cooperação; IX. Das Infrações e Penalidades Administrativas; X. Das Disposições Finais e Transitórias.

O Capítulo VII - Do emigrante, com composição por 02 Seções, sendo estas, Seção I: Das Políticas Públicas para os Emigrantes e Seção II: Dos Direitos do Emigrante. Aquela seção engloba o art. 77, informante sobre políticas públicas oferecidas pelo Estado aos migrantes, devendo obedecer aos seguintes princípios e diretrizes - prestação de assistência consular por intermédio de representações no Brasil e no exterior; oferecimento de condições mínimas para suporte dos serviços relativos à educação, saúde, trabalho, previdência social e cultura.

Segue abaixo redação do art. 77, Lei de Migração:

Art. 77. As políticas públicas para os emigrantes observarão os seguintes princípios e diretrizes:

I - proteção e prestação de assistência consular por meio das representações do Brasil no exterior;

II - promoção de condições de vida digna, por meio, entre outros, da facilitação do registro consular e da prestação de serviços consulares relativos às áreas de educação, saúde, trabalho, previdência social e cultura;

[...]

VI- esforço permanente de desburocratização, atualização e modernização do sistema de atendimento, com o objetivo de aprimorar a assistência ao emigrante [...]. (BRASIL, 2017, grifo nosso).

Com esse artigo garantiu-se a assistência jurídica integral pública, sem distinção de nacionalidade, note-se, durante muito tempo, era controversa sua utilização; o acesso ao trabalho é incentivado, muito embora, ainda, contenha a utilização da mão de obra migrante de jeito distorcido pelos empregadores nacionais, havendo o desrespeito no tocante à aplicação das regras contidas na Consolidação das Leis Trabalhistas (CACCIAMALI, 2006, p. 132). A moradia, outro direito fora prestigiado, dada a devida atenção, tendo em vista, a burocracia para a sua obtenção e registro de propriedade, principalmente, quando se referia aos estrangeiros.

Permite o acesso à prestação governamental de saúde, assistência e previdência social, sem nenhuma discriminação em função da nacionalidade e condição migratória, com base nesta normativa, a expectativa é o fim da divergência dos Tribunais Estaduais e Federais nos julgamentos dos referidos institutos. E, novamente, é frisado o acesso à educação - direito 
social basilar de uma sociedade para o desenvolvimento econômico, cultural e social (OLIVEIRA, 1999, p. 63).

O direito à saúde porta previsão na ordem Internacional e no âmbito doméstico. Em observação à Constituição da Organização Mundial da Saúde - é notável em seu preâmbulo o principal objetivo, não estando apenas na preservação da saúde em sentido físico, vai além, estendendo-se ao campo psicológico, nos sentimentos dos indivíduos, a finalidade é alcançar o ápice da felicidade, busca-se o bem-estar, os mecanismos empregados não se restringem àquele, estendendo-se às esferas de compleição que o ser humano não pode tatear (OMS, 1946).

Paulo Henrique Gonçalves Portela, no que diz respeito às características da aludida Organização Mundial da Saúde:

\begin{abstract}
A Organização Mundial da Saúde (OMS) trabalha para estabelecer padrões mínimos de cuidados à saúde em todo o mundo e garantir o direito à saúde para todas as pessoas. É o organismo especializado responsável por coordenar as negociações e ações internacionais em matéria de saúde, formatar a agenda de pesquisas nessa área, estabelecer normas e articular políticas públicas de saúde e monitorar as condições sanitárias no mundo. Sua ação abrange também o saneamento básico, a nutrição, a higiene, os medicamentos, o ensino na área de saúde [...]. (PORTELA, 2012, p. 272-273).
\end{abstract}

Na esfera nacional, o direito à saúde está expresso na Lei $n^{\circ}$ 8.080, de 19 de setembro de 1990, oferecendo entendimento das formas empenhadas para desenvolver a saúde, a disposição e as modalidades de préstimos (BRASIL, 1990). Pela vereda do Sistema Único de Saúde - vale-se o empreendimento dos mecanismos de prestação de utilidade social -, destinada a toda a população, existindo, também, a saúde na rede particular, esta modalidade permite que o cidadão disponha de pecúnia para desfrutar da proficuidade sanitária.

É observável, o art. 77, da nova Lei de Migração (2017), trouxe de forma expressa a garantia do empenho às ações públicas, cujo principal objetivo é resguardar os direitos fundamentais e sociais disciplinados na Magna Carta, desta forma, é afirmada não apenas em seu corpo, enquadrando, também, força na esfera infraconstitucional.

Além disso, é notável as diversas atividades empenhadas pelo Estado com designo de oferecer aos cidadãos o mínimo de acesso às garantias. Assente a Magna Carta em seu art. $5^{\circ}$, do qual afirma que "todos são iguais perante a lei, sem distinção de qualquer natureza, garantindo aos brasileiros e aos estrangeiros residentes no Brasil todos os direitos 
fundamentais", deste aspecto, os estrangeiros passam com os mesmos direitos dos brasileiros natos (BRASIL, 1988).

Veja-se o entendimento referente aos direitos sociais ofertados aos indivíduos, segundo Robert Alexy ${ }^{4}$ :

Direitos a prestação em sentido estrito são direitos do indivíduo, em face do Estado, a algo que o indivíduo, se dispusesse de meios financeiros suficientes e se houvesse uma oferta suficiente no mercado, poderia também obter de particulares. Quando se fala em direitos fundamentais sociais, como, por exemplo, direitos à assistência à saúde, ao trabalho, à moradia e à educação, quer-se primariamente fazer menção a direitos a prestação em sentido estrito. (ALEXY, 2008, p. 499).

Infere-se do entendimento do autor a importância dos direitos sociais no ordenamento jurídico dos Estados. Observando-o sobre a luz da Constituição de 1988, em seu forte posto no artigo $12, \S 2^{\circ}$, no qual, dispõe a não diferenciação entre os brasileiros natos e os estrangeiros, ressalvando os casos previstos na Magna Carta. Note-se, ainda, a relevância da novel Lei de Migração, eis que trouxe diversos mecanismo e instrumentos capazes de firma a segurança do bem jurídico vida.

\section{CONSIDERAÇÕES FINAIS}

A migração é influenciada pela ordenação direta da globalização, haja vista ser esta ocasionadora das mudanças ocorridas nas esferas econômica, social, cultural e política, tendo reflexos diretamente na ordem mundial e embora o art. $5^{\circ}, \mathrm{CFRB}$, dispor sobre a igualdade de todos, perante a lei, a realidade enfrentada por muitos migrantes é outra, em virtude da situação de vulnerabilidade social em que se encontram e fazendo com que sejam vítimas de tratamentos discriminatórios.

Os principais direitos sociais estão no art. $6^{\circ}$, da Constituição Federal da República Federativa do Brasil: direito à educação, à saúde, à alimentação, à moradia, ao transporte, ao lazer, à segurança, à previdência social, à proteção à maternidade e à infância e à assistência aos desamparados. Havendo diversas leis que disciplinam tais direitos, não existindo distinção entre os indivíduos que possuem ou não nacionalidade brasileira, desde que residentes no País.

\footnotetext{
${ }^{4}$ Robert Alexy, é um dos juristas alemães de maior relevância quando o assunto é destinado a matéria de direitos sociais, suas obras já tiveram tradução em mais de 19 Estados, dentre as suas principais obras está a Teoria dos Direitos Fundamentais, da qual possui tradução no Brasil pela editora Malheiros, cuja tradução fora realizada por Virgílio Afonso da Silva, sendo este Professor Titular junto à Universidade de São Paulo.
} 
A Nova Lei de Migração tem sido vista como mais um instrumento de realização dos direitos garantidos na Magna Carta de 1988, trazendo em seu corpo normas que garante a preservação do princípio da dignidade da pessoa humana, veja-se o artigo $4^{\circ}$, da nova lei, que garante no território nacional a igualdade de direitos aos migrantes e nacionais, a previsão do art. $5^{\circ}$, da Constituição Federal, tais como garantia à vida, um dos mais importantes direitos, à liberdade, seja esta física ou mental, à igualdade entre todos, sem qualquer forma de diferença, à segurança e à propriedade.

Em estudo ao Fluxo Migratório na Fronteira de Mato Grosso do Sul pelo período compreendido entre 2011 a 2016, albergou a divisão de estudo entre 03 Municípios, quais sejam, Corumbá, Ponta-Porã e Mundo Novo. Tanto quanto tabelas anexadas no corpo do presente artigo, reúnem-se diversas nacionalidades migratórias. Desde os países que fazem parte da América do Sul e possuem divisa com o Mato Grosso do Sul (Paraguai e Bolívia), chegando aos países da América Central (México), Ásia (Japão) e Europa (Alemanha, Reino Unido, França e Espanha).

De acordo com as informações obtidas junto à Delegacia da Polícia Federal de Corumbá, a reunião de todos os migrantes que adentraram pela fronteira destes 03 municípios no período quinquenal citado, perfazem um total de 414.001 indivíduos.

Corumbá recebeu um total de 325.032 indivíduos, sendo que, 209.9887 são bolivianos, 66.448 peruanos, 9.257 paraguaios, entre outros; as principais razões para este elevado número de migrantes é caracterizado pela proximidade da faixa terrestre, e, ainda, pela busca de saúde, educação e trabalho.

Ponta-Porã teve um total de 88.697 migrantes cruzando suas fronteiras, sendo estes, 72.843 são peruanos, 2.535 argentinos, 618 bolivianos, entre outros; uma das principais fontes de renda do referido município é o comércio, a utilização de ofício prestado ao estrangeiro é recorrente, em muitas situações ocorrem a exploração da referida mão de obra, observando a necessidade econômica em que muitos se encontram.

Mundo Novo, muito embora seja uma cidade fronteiriça conteve durante o período de 05 anos apenas 02 registros de migrantes, todavia, com base nas referências obtidas pelo Instituto Brasileiro de Geografia e Estatística, houve 157 estrangeiros naturalizados. Deste modo, muito embora conte com pouco registro formal do movimento migratório o número de naturalização é elevado.

Existem diversos motivos para o aumento expressivo da migração, atualmente, muitos 
indivíduos procuram o bem-estar de suas famílias, além da vasta extensão territorial. O Brasil dispõe de diversos mecanismos que está servindo de atrativo aos estrangeiros, muitos migrantes buscam como refúgio, conforme dito por questões religiosas, sociais e políticas.

Na pesquisa realizada é possível chegar às conclusões parciais de que está confirmado um aumento do fluxo migratório ao longo dos anos, tendo por principal causa a busca por melhores condições de vida e que, os principais obstáculos encontrados são a fruição de direitos sociais, todavia, espera-se que com a nova Lei brasileira de migração que a realidade fática encontrada seja alterada, principalmente em relação aos direitos trabalhistas (desrespeito ao obreiro estrangeiro), e ao atendimento à saúde pelo SUS - Sistema Único de Saúde.

\section{REFERÊNCIAS}

ACNUR. Family Reunification $\mathbf{n}^{\circ}$. 24 (XXXII) - 1981. Disponível em: <http://www.unhcr.org/excom/exconc/3ae68c43a4/family-reunification.html>. Acessado em: 01 de junho de 2018.

ALEXY, Robert. Teoria dos Direitos Fundamentais. 2. ed. São Paulo: Malheiros, 2008.

BAENINGER, Rosana. Deslocamentos Populacioanis, Urbanização e Regionalização. In: Revista Brasileira de Estudos de População. Revista Brasileira de Estudos de População (Impresso). v. 15, p. 25-38, 1998.

BRASIL. Constituição da República Federativa do Brasil de 1988. Disponível em: <http://www.planalto.gov.br/ccivil_03/constituicao/constituicaocompilado.htm>. Acessado em: 25 de maio de 2018.

Decreto-Lei $\mathbf{n}^{\circ}$ 2.848, de 7 dezembro de 1940. Código Penal. Disponível em: <http://www.planalto.gov.br/ccivil_03/decreto-lei/Del2848compilado.htm> acessado em: 14 de abril de 2017.

Lei $\mathbf{n}^{\circ}$ 13.445, de março de 2017. Disponível em: <http://www.planalto.gov.br/ccivil_03/leis/L13.345.htm>. Acessado em: 28 de fevereiro de 2018.

Lei $n^{\circ}$ 8.080, de 19 de setembro de 1990. Disponível em: < http://www.planalto.gov.br/ccivil_03/decreto-lei/Del2848compilado.htm>. Acessado em: 29 de maio de 2017.

Lei $\mathbf{n}^{0}$ 6.815, de 19 de agosto de 1980. Disponível em:

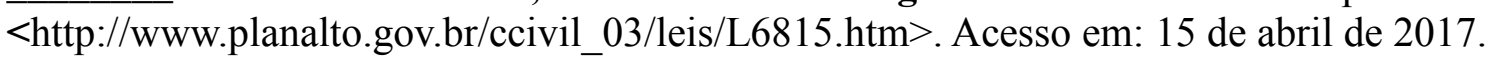


Presidência da República. Secretaria de Direitos Humanos. Manual de Recomendações de Rotinas de Prevenção e Combate ao Trabalho Escravo de Imigrantes: Secretaria de Direitos Humanos - SDH - Brasília, 2013.

CACCIAMALI, Maria Cristina. Entre o tráfico humano e a opção da mobilidade social: os imigrantes bolivianos na cidade de São Paulo. Cadernos Prolam/USP, v. 5, n. 8, p. 129-143, 2006.

CALEGARI, Marília et al. " Felicidade Clandestina": refúgio e família no Brasil. 2014.

CAMPELLO, Lívia Gaigher Bósio; DA SILVEIRA, Vladmir Oliveira. Cidadania e direitos humanos. Revista Interdisciplinar de Direito, v. 8, n. 01, p. 87-104, 2011.

FERNANDES, Ana Carolina Sores; SILVEIRA, Vladmir Oliveira. A Crise dos Refugiados na União Europeia e a Proteção dos Direitos Humanos sob a perspectiva do Estado Constitucional Cooperativo. In: IENSUE, Geziela; CARVALHO, Luciani Coimbra (Orgs.) A Ordem Internacional no Século XXI: direitos humanos, migração e cooperação jurídica. Rio de Janeiro: Ed. Lumen Juris, 2017.

GIOVANELLA, Lígia. Saúde nas fronteiras: acesso e demandas de estrangeiros e brasileiros não residentes ao SUS nas cidades de fronteira com países do MERCOSUL na perspectiva dos secretários municipais de saúde. Disponível em: <http://www.scielo.br/scielo.php?script=sci_arttext\&pid=S0102-311X2007001400014>. Acessado em: 30 de maio de 2017.

GOIS, Pedro. Do ruir do muro de Berlim a uma Europa sem fronteiras. In: BAENIGER, Rosana; CANALES, Alejandro (Org.). Migrações Fronteiriças. Campinas: NEPO, 2018, p. $51-55$ Disponivel em: http://www.nepo.unicamp.br/publicacoes/livros/mig_fronteiricas.pdf $>$. Acesso em: 03 de jul. 2018.

IBGE, Censo Demográfico, 2010.

MEZZAROBA, Orides, MONTEIRO, Cláudia Servilha. Manual de metodologia da pesquisa no direito. 7. ed., São Paulo: Saraiva, 2017.

OLIVEIRA, Romualdo Portela de. O Direito à Educação na Constituição Federal de 1988 e seu restabelecimento pelo sistema de Justiça. Revista Brasileira de Educação, v. 11, p. 61-74, 1999.

OLIVEIRA. F.C; GOMES, E.B; GONÇALVES. Migração Cidadania e Direitos Fundamentais na Tríplice Fronteira. In: IENSUE, Geziela; CARVALHO, Luciani Coimbra (Orgs.) A Ordem Internacional no Século XXI: direitos humanos, migração e cooperação jurídica. Rio de Janeiro: Ed. Lumen Juris, 2017. 
OMS. Constituição da Organização Mundial da Saúde. Disponível em: $<$ http://www.direitoshumanos.usp.br/index.php/OMS-Organiza\%C3\%A7\%C3\%A3o-

Mundial-da-Sa\%C3\%BAde/constituicao-da-organizacao-mundial-da-saude-omswho.html>. Acesso em: 20 de maio de 2017.

PORTELA, Paulo Henrique Gonçalves. Direito Internacional Público e Privado: Incluindo noções de direitos humanos e direito comunitário, 4. Ed. Salvador. Juspodvm. 2012.

SOUSA SANTOS, Boaventura de. Por uma concepção multicultural de direitos humanos. São Paulo: Revista Lua Nova. Vol. 39, 1997.TORRADO, Jesus Lima. Problema fundamental da migração. In: AGUILERA URQUIZA, A. H. (Org.) Fronteira dos Direitos Humanos Direitos Humanos nas fronteiras. Campo Grande: Ed. UFMS. 2016.

VERGARA, Sylvia Constant. Projetos e relatórios de pesquisa em administração. 2. ed. São Paulo: Atlas, 1998. 